HUNGARIAN AGRICULTURAL ENGINEERING

$N^{\circ} 26 / 2014$ 16-19

Published online: http://hae-journals.org/

HU ISSN 0864-7410 (Print) / HU ISSN 2415-9751(Online)

DOI: 10.17676/HAE.2014.26.16
PERIODICAL OF THE COMITTEE OF AGRICULTURAL AND BIOSYSTEM ENGINEERING OF THE HUNGARIAN ACADEMY OF SCIENCES and SZENT ISTVÁN UNIVERSITY Faculty of Mechanical Engineering

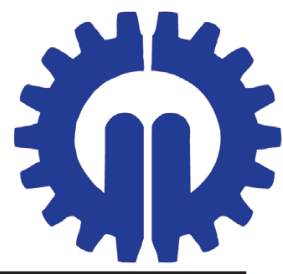

\title{
APPLICATION OF NUMERICAL ANALYSIS FOR THE DESIGN OF ROTATING TOOLS
}

\author{
Author(s): \\ T. Major ${ }^{1}-$ V.Csanády ${ }^{2}$
}

\section{Affiliation:}

'University of West -Hungary, Faculty of Forestry, Institute of Forest- and Environmental Techniques H-9400 Sopron, Ady E. st. 5.,

2University of West -Hungary, Faculty of Forestry, Institute of Mathematics, H-9400 Sopron, Ady E. st. 5.,

\section{Email address:}

major@emk.nyme.hu, vcsanady@emk.nyme.hu

\begin{abstract}
By modelling the interaction of the tool and the soil, development time and costs can be significantly reduced. Since the operation of the rotating tool involves large forces and displacements, traditional finite element methods cannot be applied. Instead, we turned to a combined FEM/SPH simulation. Using the combined FEM/SPH simulation, the horizontal force acting upon the rotating tool as a function of time was determined at $1 \mathrm{~km} / \mathrm{h}$ and $1.5 \mathrm{~km} / \mathrm{h}$ forward speeds. By fitting a function to the results of the simulation, the value of the average and maximum horizontal forces was obtained. For setting up the geometry, first we created the model of the soil surrounding the tool using the DesignModeler module of the Ansys software
\end{abstract}

\section{Keywords}

soil tiller, soil and the soil-tool interaction, Solid Edge software, Ansys software

\section{Introduction}

The soil tiller equipment investigated has a rotating tiller with four knives, the knives having an $\operatorname{arc}(\mathrm{R}=340 \mathrm{~mm})$ and three pairs of wings having decreasing widths towards the free end $(55 \mathrm{~mm}$, $45 \mathrm{~mm}$ and $35 \mathrm{~mm}$ ). The placement of the wings is perpendicular to the arc of the knives, and the knives bend back with regards to the direction of the rotation. The edges of the knives and the wings are sharpened to $50^{\circ}$ to ease their penetration into the soil. We created a geometrical model of the rotating tool (Figure 1) using Solid Edge software and used Ansys 13 finite element program for the numerical analysis.

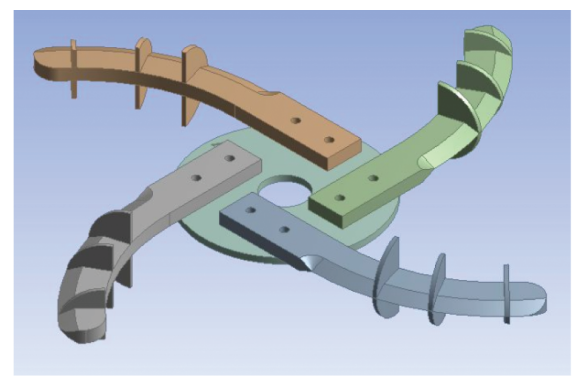

Figure 1. Geometrical model of the rotating tool

\section{Material and method}

For setting up the geometry, first we created the model of the soil surrounding the tool using the DesignModeler module of the Ansys software. The surface of the soil was set at $200 \mathrm{~mm}$ from the axis of the tool, thus, given the size of the tiller, the working depth was $220 \mathrm{~mm}$. We created a $1100 \mathrm{~mm}$ long, 600 $\mathrm{mm}$ wide and $350 \mathrm{~mm}$ deep soil trough around the tool (Figure 2).

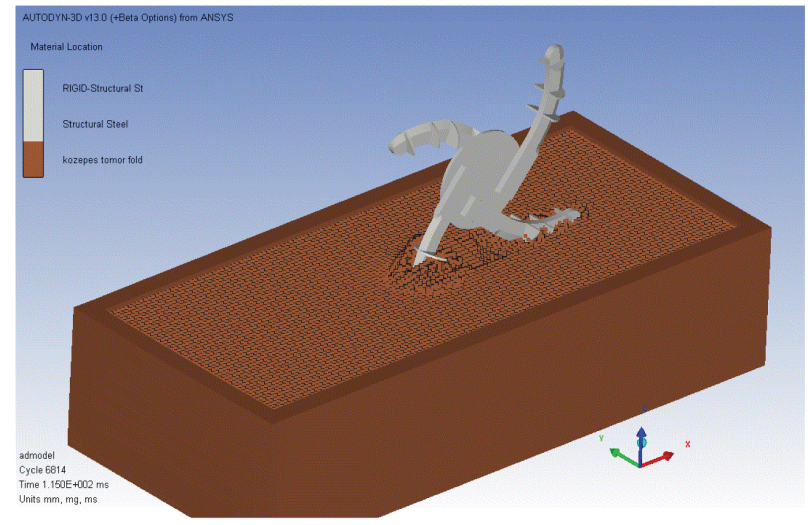

Figure 2. The rotating tool and the soil trough

We did some simplification on the geometrical model to improve the mesh, that is, we removed the screw holes and the axle hole.

During the modelling tetrahedral elements were used for the mesh of the tool.

We considered the tiller a solid body and used Drucker-Prager model (Bojtár, 1988) for the description of the mechanical properties of the soil. The Drucker-Prager model is a modification of the Mohr-Coulomb mechanical model. The D-P has a cone shape in the principal stress field (Figure 3) and therefore this shape does not introduce numerical problems on the plasticity surface.

The basic data for the mechanical model (medium soil compactness) come from measurements carried out at the Geotechnical Department of the Faculty of Civil Engineering of the Budapest University of Technology and Economics (Mouazen - Neményi - Horváth, 1998), since no such investigation has been conducted for forest soils. 


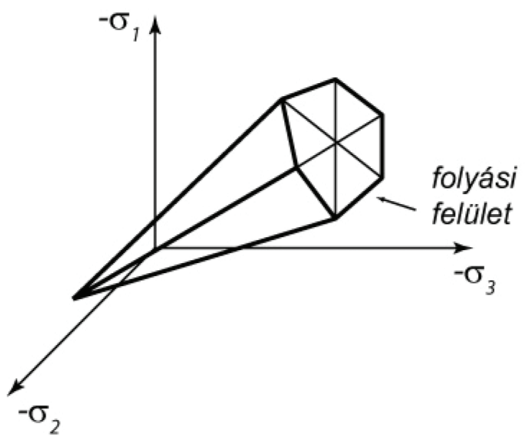

a)

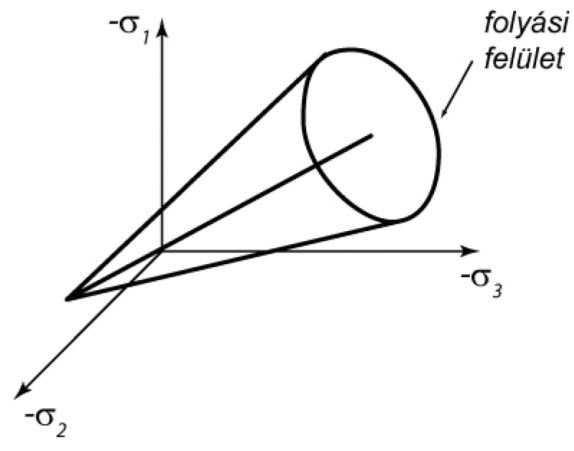

b)

Figure 3. Yield criterion for 3D stress state (a) Mohr-Coulomb model; (b) Drucker-Prager model

Chart 1. Properties of the soil and the soil-tool interaction

\begin{tabular}{|l|c|}
\hline \multicolumn{1}{|c|}{ Property } & Value \\
\hline Soil properties: & \\
\hline - cohesion [kPa]: & 15,5 \\
\hline - inner friction angle [deg]: & 31,8 \\
\hline - density [kg/m $\left.{ }^{3}\right]:$ & 1731 \\
\hline - Poisson's ratio: & 0,3596 \\
\hline - Young's modulus [kPa]: & 8067 \\
\hline Properties of the soil-tool interaction: & 23 \\
\hline - friction angle between soil and metal [deg]: & 0 \\
\hline - adhesion between soil and metal [kPa]: & \\
\hline
\end{tabular}

The operation of the rotating tool (simultaneous linear and rotational motions) is a transient phenomenon, during which large forces or displacements can occur. The finite element method (FEM) is suitable only for small forces and displacements, because for large displacements, the continuity of the finite element mesh is broken and the simulation stucks. A traditional FEM is practically incapable of modelling material discontinuities, therefore we used a combined FEM-SPH simulation for modelling the interaction between the soil and the tool. The tool was built up from traditional finite elements and the soil from SPH elements. SPH (Smooth Particle Hydrodynamics), unlike FEM, is a completely mesh-independent numerical method (Gingold - Monaghan, 1977; Monaghan, 1988; Monaghan, 1992), originally applied for astronomical calculations and later for modelling fluid mechanics. Recently, it has been successfully used for modelling landslides (Bui H. H. et. al., 2008).

SPH elements can be thought of as independent particles with certain properties (e.g. mass, density etc.) whose position and speed is known for any moment in time. They are not tied to a node, they can experience any amount of displacement. A radius is given for each particle, such that the algorithm considers every other particle within a distance twice that radius a neighbour. The physical properties of a particle are calculated from the properties of its neighbours using a special weight function that we choose. A great advantage of SPH simulations is that bodies can undergo substantial deformations, splinter, mix up with each other, without practically hindering the calculation.

We chose $14 \mathrm{~mm}$ for the size of the SPH elements. The number of SPH elements in the calculation was 147885 and the elements in the FEM mesh was 34446.

Constraints were used to stop the tool from sinking or slewing.

\section{Results and conclusion}

Running the simulation at $1 \mathrm{~km} / \mathrm{h}$ and $1.5 \mathrm{~km} / \mathrm{h}$ forward speed and 58 RPM yielded a horizontal reaction force acting upon the tool, shown on Figure 4. In spite of the noise, a sinusoid function can be observed. The reason for this is that the part of the tool immersed in the ground is changing continuously.

Part Summary (Ident 0 - admodel )

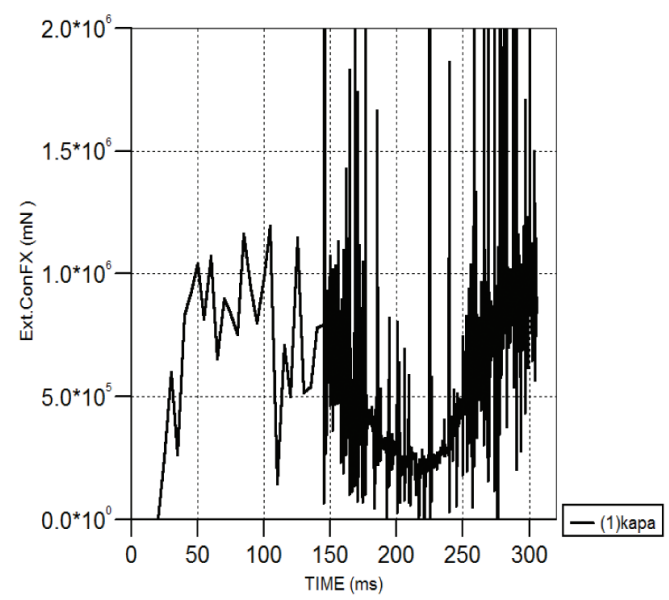

Figure 4. Traction force as a function of time, at $1 \mathrm{~km} / \mathrm{h}$ forward speed

In order to determine the average and maximum tractive force, we fitted a sinusoid function on the data points using the software STATISTICA, and carried out a correlation analysis. 


$$
\operatorname{var} 2=b_{3} \cdot \sin \left(b_{2} \cdot\left(\operatorname{var} 1-b_{1}\right)\right)+b_{0}
$$

where:

var2: horizontal reaction force $[\mathrm{mN}]$, var1: time [ms].

$\mathbf{b}_{\mathbf{0}}, \mathbf{b}_{1}, \mathbf{b}_{2}, \mathbf{b}_{3}$ are coefficients of the function with values shown in chart 2 .

Chart 2. Coefficients of the function and its correlation coefficient

\begin{tabular}{|c|c|c|c|c|c|}
\hline $\begin{array}{c}\text { Forward speed } \\
{[\mathrm{km} / \mathrm{h}]}\end{array}$ & $\boldsymbol{b}_{\boldsymbol{0}}$ & $\boldsymbol{b}_{\boldsymbol{1}}$ & $\boldsymbol{b}_{\boldsymbol{2}}$ & $\boldsymbol{b}_{\boldsymbol{3}}$ & $\boldsymbol{R}$ \\
\hline $\mathbf{1}$ & 322478 & 0,030228 & 366,4032 & 559621,3 & 0,76605 \\
\hline $\mathbf{1 , 5}$ & 355581 & 0,033438 & 237,8738 & $\mathbf{6 3 5 9 2 0 , 9}$ & $\mathbf{0 , 6 7 3 6 6}$ \\
\hline
\end{tabular}

By refining the data, the value of the correlation coefficient can be improved (to $\mathrm{R}=0,89344$ ) but the shape of the function remains substantially the same.

The coefficients of the function lead to an average tractive force of $560 \mathrm{~N}$ and maximal tractive force of $882 \mathrm{~N}$ at $1 \mathrm{~km} / \mathrm{h}$; and an average tractive force of $636 \mathrm{~N}$ and maximal tractive force of 992 $\mathrm{N}$ at $1.5 \mathrm{~km} / \mathrm{h}$.

The fitted functions and the data points are shown on Figures 5 and 6.

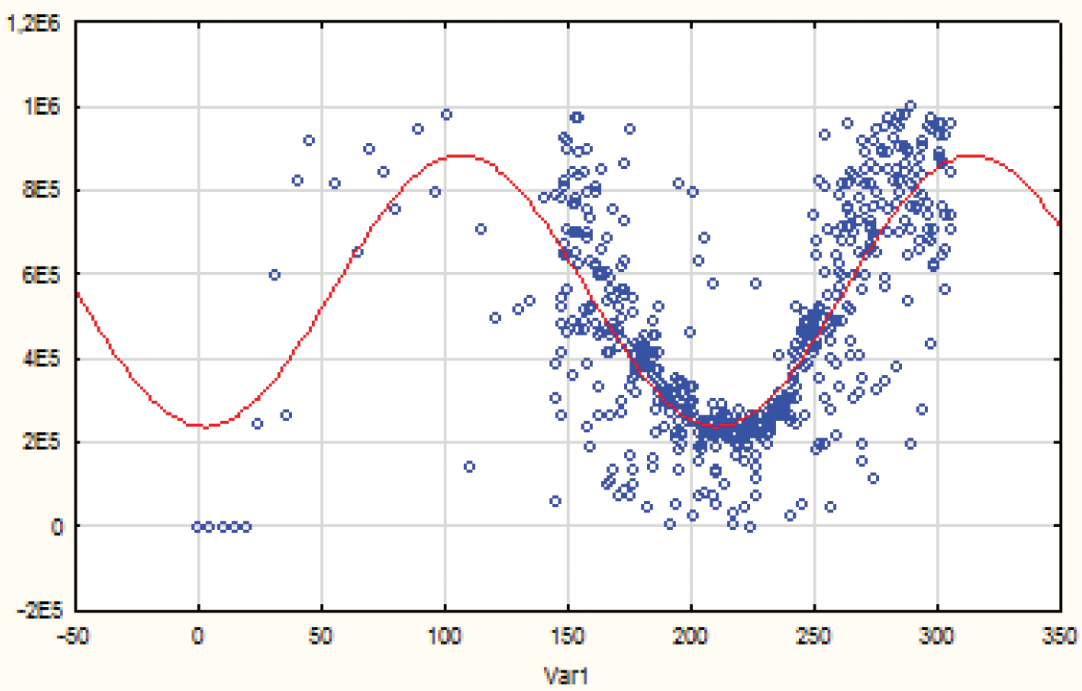

Figure 5 . Fitted function at $1 \mathrm{~km} / \mathrm{h}$ tractor speed

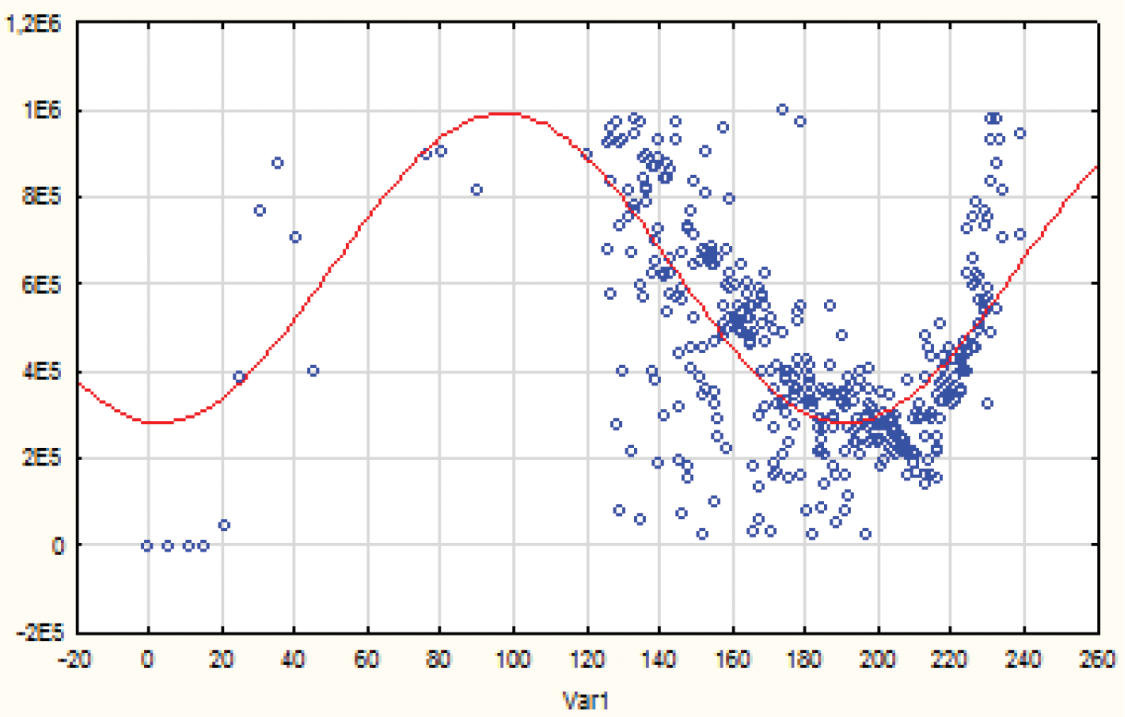

Figure 5. Fitted function at $1 \mathrm{~km} / \mathrm{h}$ tractor speed 


\section{Summary}

Earlier equipment, including cultivation tools, were designed by relying on practical experience, largely without theoretical investigation. The investigation and modelling of tools is nowadays an important part of the development process of new agricultural equipment. The precise mechanical sizing of a new tool must be carried out through field tests and modern mathematical-mechanical methods (finite element method). By modelling the interaction of the tool and the soil, development time and costs can be significantly reduced.

Since the operation of the rotating tool involves large forces and displacements, traditional finite element methods cannot be applied. Instead, we turned to a combined FEM/SPH simulation. Using the combined FEM/SPH simulation, the horizontal force acting upon the rotating tool as a function of time was determined at $1 \mathrm{~km} / \mathrm{h}$ and $1.5 \mathrm{~km} / \mathrm{h}$ forwad speeds. By fitting a function to the results of the simulation, the value of the average and maximum horizontal forces was obtained.

\section{References}

[1] Bojtár I. (1988): Mechanikai anyagmodellek. Tankönyvkiadó, Budapest.

[2] Bui H. H. - Fukagawa R. - Sako K. - Wells J. C. (2008): SPH-Based Numerical Simulations for Large Deformation of Geomaterial Considering Soil-Structure Interaction. The 12th International Conference of International Association for Computer Methods and Advances in Geomechanics (IACMAG), 1:570-578.

[3] Gingold R. A. - Monaghan J. J. (1977): Smoothed Particle Hydrodynamics: theory and application to non-spherical stars. Mon. Not. R. astr. Soc. 181:375-389.

[4] Monaghan J. J. (1988): An introduction to SPH. Computer Physics Communications. 48:89-96.

[5] Monaghan J. J. (1992): Smoothed Particle Hydrodynamics. Annu. Rev. Astron. Astrophys. 30:543-574.

[6] Mouazen A. M. - Neményi M. - Horváth B. (1998): Investigation of Forestry deep subsoiling by the finite element method. Hungarian Agricultural Engineering. 11:47-49. 